УДК: 796.332-057.874

\title{
МІНІ-ФУТБОЛ ЯК ОСОБЛИВИЙ ВИД ФІЗИЧНОГО ВДОСКОНАЛЕННЯ СТУДЕНТОК У ПРОЦЕСІ НАВЧАННЯ
}

\author{
Олег Мазурчук ${ }^{1}$, Олександр Панасюк $^{1}$ Олександр Митчик ${ }^{1}$, Петро Герасимюк, \\ Анатолій Хомич ${ }^{2}$ \\ ${ }^{1}$ Східноєвропейський національний університет імені Лесі Українки, Луцьк, Україна, \\ Mazurchuk.Oleh@eenu.edu.ua \\ ${ }^{2}$ Луцький національний технічний університет, Луцьк, Україна
}

https://doi.org/10.29038/2220-7481-2020-03-52-57

\begin{abstract}
Анотації
Aктуальність. Основним завданням дисципліни «Фізичне виховання» в закладі вищої освіти $є$ розвиток у студентів фізичних якостей та рухових здібностей. Виконанню цього завдання сприяє залучення студентської молоді до різноманітних секційних занять, зокрема міні-футболу, який користується популярністю не лише серед осіб чоловічої, а й жіночої статі. Мета роботи - висвітлення основних засобів забезпечення оптимального рівня розвитку фізичних якостей студенток, які займаються в секції міні-футболу. Методи - аналіз і синтез наукових літературних джерел, педагогічне спостереження, узагальнення експериментальних досліджень науковців та систематизація отриманих результатів дослідження. Результати. Рухова діяльність у міні-футболі характеризується різноманітними діями, зокрема бігом різної інтенсивності, ходьбою, стрибками, ударами по м'ячу, зупинками, падінням, фінтами тощо. Тому надзвичайно важливою якістю футболісток $\epsilon$ швидкість. Швидкий гравець може виграти час у суперника, має можливість успішно виконувати тактичні завдання. Спритний - легко оволодіває новими технічними прийомами, краще пристосовується до різних ігрових умов, здатний точно, економно, швидко виконувати нове рухове завчання. Футболістки мають справу з постійною власною вагою й вагою м’яча, тому їм потрібна раціональна сила, яка б відповідала вимогам ігрової діяльності. Протягом гри спортсменки виконують багаторазові спринтерські прискорення, що вимагають витривалості. У міні-футболі важливе значення має еластичність м'язів і зв'язок нижніх кінцівок та хребта, тому на заняттях потрібно приділяти значну увагу розвитку гнучкості. Висновки. Навчання й тренування в міні-футболі невід'ємні частини єдиного педагогічного процесу, у якому потрібно дотримуватися основних положень, а відмінних результатів можна досягти лише за умови високого рівня фізичної та технічної підготовленості гравців. Правильно обрана методика навчання та вдала організація занять досить важливі в підготовці жіночої команди.
\end{abstract}

Ключові слова: міні-футбол, студентки, підготовка, фізичні якості, засоби, методи.

Олег Мазурчук, Александр Панасюк, Александр Митчик, Петр Герасимюк, Анатолий Хомич. Минифутбол как особенный вид физического совершенствования студенток в процессе учебы. Актуальность. Основным заданием дисциплины «Физическое воспитание» в заведении высшего образования является развитие у студентов физических качеств и двигательных способностей. Решению этой задачи способствует привлечение студенческой молодежи к разнообразным секционным занятиям, в частности по мини-футболу, который пользуется популярностью не только среди лиц мужского, но и женского пола. Цель данной работы освещение основных средств обеспечения оптимального уровня развития физических качеств студенток, которые занимаются в секции мини-футбола. Memodb - анализ и синтез научных литературных источников, педагогическое наблюдение, обобщение экспериментальных исследований научных работников та систематизация полученных результатов исследования. Результаты. Двигательная деятельность в мини-футболе характеризуется самыми разнообразными действиями, в частности бегом разной интенсивности, ходьбой, прыжками, ударами по мячу, остановками, падением, финтами и т. п. Поэтому чрезвычайно важным качеством футболисток является скорость. Быстрый игрок может выиграть время у соперника, имеет возможность успешно решать тактические задания. Ловкий - легко овладевает новыми техническими приемами, лучше приспосабливается к разным игровым условиям, способный точно, экономно, быстро выполнять новую двигательную задачу. Футболистки имеют дело с постоянным собственным весом и весом мяча, поэтому им нужна рациональная сила, которая бы отвечала требованиям игровой деятельности. В течение игры спортсменки выполняют многоразовые спринтерские ускорения, которые требуют выносливости. В минифутболе важное значение имеет эластичность мышц и связок нижних конечностей, а также позвоночника. Поэтому на занятиях следует уделять значительное внимание развитию гибкости. Bыводы. Обучение и тренировка в мини-футболе - неотъемлемые части единственного педагогического процесса, в котором следует придерживаться основных положений, а отличных результатов можно достичь лишь при условии высокого

52 ISSN 2410-2156 (Online), ISSN 2220-7481 (Print)

(C) 2020 Східноєвропейський національний університет імені Лесі Українки. Ця стаття відкритого доступу на умовах CC BY-NC 4.0 
уровня физической и технической подготовленности игроков. Правильно избрана методика обучения и удачный выбор организации занятий достаточно важны в подготовке женской команды.

Ключевые слова: мини-футбол, студентки, подготовка, физические качества, средства, методы.

Oleh Mazurchuk, Oleksandr Panasiuk, Oleksandr Mytchyk, Petro Herasymiuk, Anatoliy Khomych. MiniFootball as a Special Kind of Physical Improvement of Female Students in the Training Process. Research Relevance. The main task of the discipline «Physical education» in higher education institutions is the development of physical qualities and motor abilities of students. Student youth' engagement in diverse sectional classes contributes to the solution of this issue, mini-football in particular, which is acceptable among not only males but also females. The Research Aims to highlight the principal means of ensuring the optimal level of the development of physical qualities of female students engaged in mini-football sections. Research Methods include analysis and synthesis of scientific literature sources, pedagogical observation, generalization of experimental studies of scientists, and systematization of the obtained research findings. Research Results. Motor activity in mini-football is characterized by the wide variety of actions, in particular: different intensity running, walking, jumping, kicks, stops, falls, feints, and the like. Therefore, speed is the most significant quality of female football players. A fast player can gain time from the opponent and can solve tactical tasks successfully. A smart player freely masters new techniques, better adopts to the different game conditions, can accurately, efficiently, and quickly perform new motor skills. Female players deal with the constant own weight and weight of the ball, as they need a rational strength that would meet the requirements of the play activity. During the game, female athletes perform multiple sprint accelerations that require endurance. In mini-football, muscle elasticity and ligaments of lower extremities and spine are very significant; therefore, much attention during training should be paid to flexibility. Conclusions. Education and training in mini-football are integral parts of a single pedagogical process, in which the basic principles should be followed, and excellent results can be achieved only under the conditions of high level of physical and technical preparedness of players. Properly chosen training methods and successful organization of classes are very significant in preparation of a women's team.

Key words: mini-football, female students, preparation, physical qualities, means, methods.

Вступ. Піднесення ролі фізичної культури в зміцненні здоров'я населення є сьогодні одним із головних завдань нової України. Особливо важливе значення фізичної культури і спорту для студентів, високий рівень здоров’я та різнобічний фізичний розвиток яких - запорука успішної реалізації соціально-економічних перетворень нашого суспільства [14].

Аналіз науково-методичної літератури $[4 ; 7 ; 13 ; 16]$ свідчить, що зміцнення й збереження здоров'я людини можливе лише за умови систематичних занять фізичними вправами та спортом. До ефективних форм організації навчального процесу 3 фізичного виховання відносять спортивну спрямованість занять, які побудовані на принципах спортивного тренування, що сприяє формуванню фізичної культури студентської молоді, підвищенню іiі функціональних можливостей і гармонійного розвитку особистості. Серед великого розмаїття видів спорту особливе місце за своєю масовістю й захопленістю серед студентів займає міні-футбол, який протягом останнього десятиріччя серед ігрових видів спорту найбільш стрімко набирає обертів і стає все більш популярним завдяки його доступності, темпераменту, надто швидкому темпу, блискавичній зміні подій на майданчику. У мініфутбол можна грати на баскетбольних і гандбольних майданчиках, у спортивних залах, у хокейній коробці (улітку), а також на будь-якій місцевості за спрощеними правилами. Міні-футбол не такий жорсткий вид спорту, як великий футбол, тому він добре прижився в студентському середовищі не лише серед юнаків, а й серед дівчат. У багатьох вищих навчальних закладах створено як чоловічі, так і жіночі команди, які успішно виступають на змаганнях різних рівнів [8].

Д. В. Бондарєв [1] характеризує міні-футбол як гру, що проходить у досить інтенсивному темпі та вимагає відмінної фізичної підготовки. Гравцям протягом матчу доводиться багато разів здійснювати прискорення й миттєво стартувати 3 місця, вступати в єдиноборства 3 супротивниками та наносити удари по м'ячу, прикладаючи значні зусилля, тому порядок виконання фізичних вправ i ïx характер постійно змінюються. За мірою зростання кваліфікації футболісток коректується підхід до фізичних навантажень, а також змінюються методи, що застосовуються під час тренувань.

Мета дослідження - висвітлення основних засобів забезпечення оптимального рівня розвитку фізичних якостей студенток, які займаються в секції міні-футболу.

Методи - аналіз і синтез наукових літературних джерел, педагогічне спостереження, узагальнення експериментальних досліджень науковців і систематизація отриманих результатів дослідження.

Результати дослідження. Для міні-футболу властива різноманітність рухових навичок й ігрових дій, які відрізняються не лише за інтенсивністю зусиль, а й за координаційною структурою, що сприяє 
розвитку всіх фізичних якостей: сили, витривалості, швидкості, гнучкості та спритності. Важливо підкреслити, що під час занять міні-футболом ці якості гармонійно доповнюють одна одну [9].

А. П. Леськів [5] зауважує, що однією з провідних якостей футболісток $є$ швидкість і швидкісносилові якості. Тому для розвитку швидкості треба використовувати багато бігових вправ, зокрема біг із високого старту; старти з різноманітних положень (лежачи, стоячи на колінах, боком або спиною в сторону старту, після виконання перекиду вперед тощо); естафетний біг; біг із високим підніманням стегна, дріботливий біг; біг під гору; біг високої інтенсивності на коротких відрізках (30-50 м) 3 обтяженнями - «манжетами» на руках і ногах; стрибковий біг на 20-40м. У ролі специфічних для міні-футболу засобів, спрямованих на підвищення швидкісного потенціалу, можна використовувати також такі вправи, як швидке ведення м'яча 20-30 м, а також інші.

Ф. Г. Опанасюк і Г. П. Грибан [10] для вдосконалення швидкісних якостей рекомендують використовувати повторний та ігровий методи виконання вправ, а для підвищення швидкісносилового потенціалу футболісток - повторний, серійний і ігровий. Необхідною умовою розвитку цих якостей є незначна тривалість (до 10-15 с) та висока (максимальна, близька до максимальної) інтенсивність виконуваних вправ, водночас чисельність повторів повинна становити не більше ніж 4-5. Тривалість інтервалів відпочинку потрібно визначати за показниками частоти пульсу. За частоти пульсу 110-125 уд/хв рекомендується починати виконання наступної вправи (повторення).

Загалом розвивати швидкість і швидкісно-силові якості футболісток треба паралельно 3 вивченням та вдосконаленням технічних прийомів. Для цього рекомендується чергувати виконання легкоатлетичних вправ, проведення рухливих ігор, естафет зі специфічними футбольними вправами. Не рекомендовано на одному тренуванні проводити роботу над розвитком швидкості й витривалості [12].

Важливе значення в підготовці футболісток має вдосконалення силових здібностей. Як зазначають науковці [3], сила - це здатність переборювати зовнішній опір або протидіяти йому за допомогою м'язових зусиль. У ролі опору можуть виступати, наприклад, маса обтяжень предметів, спортивного знаряддя; опір партнера; опір навколишнього середовища; реакція опори при взаємодії 3 нею; сили земного тяжіння, які дорівнюють масі тіла людини тощо. Чим більший опір, тим більше потрібно сили для його подолання. Загалом силові здібності поділяються на власне-силові (статичний режим, повільні рухи) і швидкісно-силові (динамічна сила, що проявляється у швидких рухах). Тому форми тренувань з інших видів спорту не можна сліпо копіювати й тренувати футболісток так само, як, наприклад, легкоатлеток. Спеціальні методи тренування, спрямовані на розвиток фізичної сили. Передусім, інтервальні тренування та постійні навантаження, можуть поєднуватися 3 технічними й тактичними заняттями, наближеними до ігрової обстановки. Монотонні заняття вбивають внутрішню активність і суперечать специфічним вимогам гри. Крім того, у міні-футболі постійно зростає значення силового єдиноборства, тому атлетична підготовка футболісток украй необхідна.

Ефективним засобом підвищення силових здібностей спортсменок $є$ рухливі ігри й естафети 3 використанням набивних м'ячів. Особливу увагу треба приділяти тим м'язам, які несуть основне навантаження під час гри. Зокрема, це згиначі й розгиначі стегна, згиначі та розгиначі гомілки, підошовний згинач стопи й інші дрібні м'язові групи нижніх кінцівок. У ролі ефективного методу організації спортсменок рекомендовано застосовувати метод колового тренування, так звану роботу «на станціях» [6].

Особливе місце в підготовці футболісток займає витривалість. Проте вдосконалюючи аеробні можливості організму, треба дотримуватися принципу «краще недовантажити, ніж перевантажити спортсменку». Тому потрібно постійно контролювати величину навантаження за допомогою підрахунку частоти пульсу.

В. Д. Гогоць, О. О. Остапова, А. В. Остапов [2] зауважують, що загальну витривалість можна розвивати, виконуючи вправи з невисокою інтенсивністю (50-75 \% від максимальної), але впродовж тривалого часу. Основними засобами розвитку цієї якості є кросовий біг, двостороння гра в баскетбол, волейбол, гандбол із невисокою інтенсивністю. Величина інтервалів відпочинку лімітується параметрами частоти пульсу - за ЧСС, що дорівнює 135-140 уд/хв., потрібно починати виконання наступної вправи.

Удосконалення спеціальної (швидкісної) витривалості футболісток, порівняно з розвитком загальної, характеризується меншою тривалістю вправ (20 c-1 хв 30 с) і більш високою інтенсивністю їх виконання (80-95 \% від максимальної). Основними засобами є повторний біг на відрізках 
від 10 до 80 м, човниковий біг, ігрові вправи з м'ячем і без, рухливі ігри, естафети. Частота пульсу, за якої треба розпочинати виконання наступної вправи (повторення), не менша ніж 130-140 уд/хв. [11].

Від ступеня розвитку координаційних здібностей спортсменок залежить ефективність оволодіння ними технікою гри в міні-футбол. Тому з перших же занять потрібно підвищувати рівень розвитку спритності. Науковці-практики [9] для розвитку спритності рекомендують добирати добре засвоєні й знайомі вправи, у якості яких можуть бути перекиди, опорні стрибки, просування стрибками між стійками (фішками, прапорцями), стрибки через набивні м'ячі й інші перешкоди, біг між стійками (м'ячами, прапорцями, фішками), стрибки вгору-уперед після розбігу та ловіння тенісного (футбольного) м'яча під час польоту (м'яч накидає партнер), виконання загальнорозвивальних вправ у заданому темпі (повільному, середньому, швидкому), із великою й малою амплітудами.

Досить ефективним у навчально-тренувальному процесі $\epsilon$ використання рухливих ігор, акробатичних вправ, вправ на розучування техніки й тактики міні-футболу, вправ із легкої атлетики, баскетболу, гандболу, волейболу. Метод виконання цих вправ - повторний, їх кількість на занятті не повинна бути великою. Розучувати нові вправи й тактичні комбінації потрібно на початку основної частини тренування, а повторювати та вдосконалювати вже вивчені - як на початку, так і в кінці заняття [6].

Крім вищезазначених рухових якостей, особливу увагу на заняттях, на нашу думку, доцільно приділяти розвитку гнучкості, оскільки в міні-футболі важливе значення має еластичність м'язів і зв'язок нижніх кінцівок та хребтового стовпа. Ефективними для розвитку цієї якості є колові рухи стопами в положенні сидячи, ноги вгору, а також у положенні лежачи на спині, ноги вгору; колові (вісімкою) рухи стопою в положенні стоячи на одній нозі, друга нога вперед; із різних вихідних положень (руки вгору, униз, у сторони, перед грудьми, з'єднані за спиною тощо) відведення прямих рук назад пружними й ривковими рухами (те саме можна виконувати з легкими гантелями); у положенні «міст» погойдування вперед-назад, випрямляючи та згинаючи ноги; із положення сидячи (ноги разом, нарізно) нахили вперед, дістаючи або захоплюючи пальці ніг; із різних вихідних положень (ноги разом, нарізно, стоячи на колінах) нахили назад. Доцільно використовувати різноманітні рухливі ігри й естафети, а також спеціально відібрані гімнастичні вправи, що виконуються 3 допомогою тренера або партнера. Виконувати вправи на розвиток гнучкості рекомендовано протягом усього заняття, починаючи зі вступної частини (розминки) й закінчуючи завершальною. Ці вправи $€$ ефективним засобом відновлення працездатності («активного» відпочинку) й можуть виконуватися під час інтервалів відпочинку [6].

Дискусія. Сьогодні фізичне виховання студентів далеке від досконалості. Простежуємо відмову від елементів традиційної системи на користь створення умов для широкого вибору студентами засобів фізичного виховання та спорту, які б відповідали їхнім запитам, інтересам, стану здоров'я, фізичній і технічній підготовці, спортивній кваліфікації. У системі фізичного виховання закладів вищої освіти чільне місце посідають спортивні ігри, зокрема міні-футбол. Завдяки його доступності й темпераменту він завоював серця багатьох студенток. Ми погоджуємося 3 думкою науковців i практиків, що цей вид фізичного вдосконалення підвищує ефективність навчального процесу, сприяє гармонійному розвитку особистості. Проте у вітчизняній і зарубіжній літературі, на нашу думку, недостатньо наукових даних та практичних рекомендацій щодо застосування спеціальних комплексів для оптимізації тренувального процесу футболісток. Ця проблема має важливе теоретичне й практичне значення для підготовки футболісток, у результаті чого одним із пріоритетних завдань сучасного жіночого футболу є пошук шляхів оптимізації процесу фізичної підготовки.

Висновки. Застосування міні-футболу як комплексного засобу фізичного виховання студенток закладів вищої освіти повністю себе виправдовує, оскільки це дуже емоційна гра, що постійно проходить у швидкому темпі, сприяє не лише фізичному розвитку, а й підвищенню психомоторних здібностей особистості. Проте, щоб досягнути максимального ефекту в діяльності жіночого мініфутболу, потрібно значно більше уваги приділяти розвитку фізичних якостей гравців, зокрема швидкості, сили, витривалості, спритності та гнучкості. Із метою забезпечення оптимального рівня розвитку цих якостей спортсменок тренер повинен використовувати низку засобів і методів. Зокрема, це комплекси різноманітних вправ як із м'ячем, так i без м'яча, рухливі ігри, естафети тощо. У тренувальному процесі він повинен ретельно стежити за тривалістю цих вправ, їх інтенсивністю й інтервалами відпочинку. Відтак правильно обрана методика навчання та вдала організація занять $€$ досить важливими в підготовці жіночої команди з міні-футболу. 
Подальшого вивчення потребують питання як теоретичних, так і методичних засад фізичного вдосконалення спортсменок у міні-футболі. Дослідження означеної проблеми стане предметом наших наступних наукових пошуків.

\section{Джерела та література}

1. Бондарев Д. В. Оценка интенсивности специфических упражнений футбола при выполнении их студентами. Фізичне виховання, спорт і культура здоров'я у сучасному суспільстві: зб. наук. праць. 2008. T. 2. C. $20-23$.

2. Гогоць В. Д., Остапова О. О., Остапов А. В. Розвиток витривалості і сили: метод. посіб. Полтава, 2010. $36 \mathrm{c}$.

3. Гришина Ю. И. Основы силовой подготовки: знать и уметь: учеб. пособие. Ростов н/Д «Феникс», 2011. $280 \mathrm{c}$.

4. Кондратович А. Б. Вплив занять футболом на показники фізичних якостей студентів. Materials of the XIII International scientific and practical conference «Cutting-edge science-2017», 30 April-07 May, 2017. Sheffield: Science and Education Ltd, 2017. Vol. 13: History. Psychology and sociology. Music and life. Physical culture and sport. C. 99-101.

5. Леськів А. П., Дзюбатинський А. Б., Левчук В. А. Підготовка юного футболіста. Тернопіль: Астон, $2001.80 \mathrm{c}$.

6. Мазурчук О. Т. Від футболу до футзалу: метод. рек. Луцьк, 2015. 84 с.

7. Маляр Е. І. Вплив засобів футболу на рівень функціональної підготовленості студентів-податківців. Педагогіка, психологія та медико-біологічні проблеми фізичного виховання і спорту: зб. наук. праць/за ред. С. С. Єрмакова. Харків, 2007. № 7. С.101-104.

8. Оксьом П. М. Динаміка розвитку фізичних якостей у студенток вищого педагогічного навчального закладу під впливом гри в міні-футбол. Молода спортивна наука Украӥни: зб. наук. праць в галузі фізичної культури та спорту. Львів: НФВ «Українські технології», 2005. Вип. 9. Т. 4. С. 161-166.

9. Опанасюк Ф. Г., Грибан Г. П. Розвиток спритності та координаційних здібностей в процесі самостійних занять студентів: метод. розроб. для викладання кафедр фіз. вих. і студентів. Житомир: ДАУ, 2004. $18 \mathrm{c}$.

10. Опанасюк Ф. Г., Грибан Г. П. Розвиток швидкості в процесі самостійних занять студентів: метод. розроб. для викладачів кафедр фіз. вих. і студентів. Житомир: ДАУ, 2004. 29 с.

11. Петров О. П. Методика навчання футболу: навч.-метод. посіб. Кам'янець-Подільський: Кам'янецьПодільський держ. ун-т, ред.-вид. відд., 2006. 128 с.

12. Савченко Р. Є. Розвиток швидкісних можливостей: метод. рек. для студентів. Хмельницький: ТУП, 1999. $22 \mathrm{c}$.

13. Соломонко В. В., Лисенчук Г. А., Соломонко О. В. Футбол: підруч. для студентів вищ. учб. закл. фіз. вих. і спорту. Київ: Олімп. літ, 1997. 288 с.

14. Цьось А., Шевчук А., Касарда О. Рухова активність у мотиваційно-ціннісних орієнтаціях студентів. Фізичне виховання, спорт і культура здоров'я у сучасному суспільстві: зб. наук. праць. 2016. № 4. C.83-87.

15. Шаповал Є. Ю., Момот Є. Ю., Свєртнєв О. А., Хоменко П. В. Фізіологічні особливості функціональної діяльності жіночого організму у процесі занять міні-футболом. Світ медицини та біології. 2018. № 2(64). C. 98-103.

16. Юрчишин Ю. В. Стан та особливості мотивації студентів до рухової активності оздоровчої спрямованості на сучасному етапі реалізації фізичного виховання у ВНЗ. Педагогіка, психологія та медико-біологічні проблеми фізичного виховання $і$ спорту: зб. наук. праць/за ред. С. С. Срмакова. Харків: ХДАДМ (ХХПІ), 2012. № 4. С.118-123.

\section{References}

1. Bondarev, D. V. (2008). Otsenka intensivnosti spetsificheskikh uprazhnenii futbola pri vypolnenii ikh studentami [Assessment of the intensity of specific soccer exercises performed by students]. Physical Education, Sport and Health Culture in Modern Society, 2, 20-23.

2. Gogots', V. D., Ostapova, O. O., Ostapov, A. V. (2010). Rozvitok vitrivalosti i sili [Development of muscular endurance and strength]: metod. posib. Poltava, 36.

3. Grishina, Yu. I. (2011). Osnovy silovoi podgotovki: znat' i umet' [Basics of strength-building activities]: ucheb. posobie. Rostov n/D «FenikS», $280 \mathrm{p}$.

4. Kondratovich, A. B. (2017). Vpliv zanyat' futbolom na pokazniki fizichnikh yakostei studentiv [The influence of soccer training on the performance of students' physical qualities]. Materials of the XIII International scientific and practical conference "Cutting-edge science-2017», 30 April-07 May. Sheffield: Science and Education Ltd, Vol. 13: History. Psychology and sociology. Music and life. Physical culture and sport, 99-101.

5. Les'kiv, A. P., Dzyubatins'kii, A. B., Levchuk, V. A. (2001). Pidgotovka yunogo futbolista [Training a young soccer player]. Ternopil': Ast, 80. 
6. Mazurchuk, O. T. (2015). Vid futbolu do futzalu [From arena soccer to indoor soccer: method. rec.]: metod. rek. Luts'k, $84 \mathrm{p}$.

7. Malyar, E. I. (2007). Vpliv zasobiv futbolu na riven' funktsional'noï pidgotovlenosti studentiv-podatkivtsiv [The impact of football on the level of functional preparedness of taxman student]. Pedagogika, psikhologiya ta mediko-biologichni problemi fizichnogo vikhovannya i sportu: zb. nauk. pr./za red. S. S. Ermakova. Kharkiv, 7, 101-104.

8. Oks'om, P. M. (2005). Dinamika rozvitku fizichnikh yakostei u studentok vishchogo pedagogichnogo navchal'nogo zakladu pid vplivom gri $\mathrm{v}$ mini-futbol [Dynamics of development of physical qualities of students of higher pedagogical institution under the influence of playing indoor soccer]. Moloda sportivna nauka Ukraïni: zb. nauk. pr. v galuzi fizichnoï kul'turi ta sportu. L'viv: NFV «Ukraïns'ki tekhnologiï», 9, 4, $161-166$.

9. Opanasyuk, F. G., Griban, G. P. (2004). Rozvitok spritnosti ta koordinatsiinikh zdibnostei v protsesi samostiinikh zanyat' studentiv [Development of dexterity and coordination skills in the process of students' self-study]: metod. rozrob. dlya viklad. kafedr fiz. vikh. i studentiv. Zhitomir: DAU, 18 p.

10. Opanasyuk, F. G., Griban, G. P. (2004). Rozvitok shvidkosti v protsesi samostiinikh zanyat' studentiv [Speed development in the process of students' self-study]: metod. rozrob. dlya viklad. kafedr fiz. vikh. i studentiv. Zhitomir: DAU, 29 p.

11. Petrov, O. P. (2006). Metodika navchannya futbolu [Teaching methods for soccer]: navch.-metod. posib. KaM'yanets'-Podil's'kii: KaM'yanets'-Podil's'kii derzh. un-t, red.-vid. vidd., 128.

12. Svirgunets', Ye. M., Savchenko, R. Ye. (1999). Rozvitok shvidkisnikh mozhlivostei [Developing speed fitnes]: metod. rek. dlya studentiv. Khmel'nits'kii: TUP, 22.

13. Solomonko, V. V., Lisenchuk, G. A., Solomonko, O. V. (1997). Futbol [Soccer]: Pidruchnik dlya studentiv vishchikh uchbovikh zakladiv fizichnogo vikhovannya i sportu. Kyiv: Olimp. lit, 288.

14. Ts'os', A., Shevchuk, A., Kasarda, O. (2016). Rukhova aktivnist' u motivatsiino-tsinnisnikh orientatsiyakh studentiv [Motor activity in students' motivational and value orientations]. Physical Education, Sport and Health Culture in Modern Society, 4, 83-87.

15. Shapoval, Ye. Yu., Momot, Ye. Yu., Svertnev, O. A., Khomenko, P. V. (2018). Fiziologichni osoblivosti funktsional'noï diyal'nosti zhinochogo organizmu u protsesi zanyat' mini-futbolom [Physiological make-up of the functional activity of the female body in the process of indoor soccer training]. Svit meditsini ta biologii, 2(64), 98-103.

16. Yurchishin, Yu. V. (2012). Stan ta osoblivosti motivatsiï studentiv do rukhovoï aktivnosti ozdorovchoï spryamovanosti na suchasnomu etapi realizatsiï fizichnogo vikhovannya u VNZ [Conditions and special aspects of students' motivation for physical activity of health orientation at the present stage of realization of physical education in universities]. Pedagogika, psikhologiya ta mediko-biologichni problemi fizichnogo vikhovannya i sportu: zb. nauk. pr./za red. S. S. Crmakova. Kharkiv: KHDADM (KHKHPI), 4, 118-123.

Стаття надійшла до редакції 28.06.2020 р. 